\title{
Viral Hepatitis in Dentistry - An overlooked contributor to disease burden and occupational hazard in India
}

Sabin Syed ${ }^{1}$, Pranav Keshan ${ }^{2}$, Aayushi Rastogi ${ }^{3}$, Arpit Kumar ${ }^{4}$, Mohit Varshney $^{5}$, Akanksha Bansal ${ }^{6}$

${ }^{1}$ Program Coordinator, Project ECHO, Institute of Liver and Biliary Science, New Delhi; ${ }^{2}$ Program Associate, Project ECHO, Institute of Liver and Biliary Science, New Delhi; ${ }^{3} \mathrm{PhD}$ Scholar, Department of Epidemiology, Institute of Liver and Biliary Science, New Delhi; ${ }^{4}$ Senior Executive (Technical), Project ECHO, Institute of Liver and Biliary Science, New Delhi; ${ }^{5}$ Associate Professor, Department of Psychiatry, Institute of Liver and Biliary Science, New Delhi; ${ }^{6}$ Senior Manager (Projects), Project ECHO, PRAKASH and LEAD, Institute of Liver and Biliary Sciences, New Delhi

\begin{tabular}{|c|c|c|c|c|c|c|c|c|}
\hline Abstract & Introduction & Methodology & Results & Conclusion & References & Citation & \multicolumn{2}{|c|}{ Tables / Figures } \\
\hline \multicolumn{9}{|c|}{ ling Author } \\
\hline \multicolumn{8}{|c|}{$\begin{array}{l}\text { Ms Akanksha Bansal, Senior Manager (Projects), Project ECHO, PRAKASH and LEAD, Institute of Liver and } \\
\text { Biliary Sciences, Vasant Kunj, Delhi - } 110070 . \\
\text { E Mail ID: akankshambansal@gmail.com }\end{array}$} & 口ing \\
\hline
\end{tabular}

\section{Citation}

Syed S, Keshan P, Rastogi A, Kumar A, Varshney M, Bansal A. Viral Hepatitis in Dentistry - An overlooked contributor to disease burden and occupational hazard in India. Indian J Comm Health. 2021;33(2):373-378. https://doi.org/10.47203/IJCH.2021.v33i02.026

Source of Funding: Nil Conflict of Interest: None declared

\section{Article Cycle}

Received: 02/03/2021; Revision: 16/04/2021; Accepted: 23/05/2021; Published: 30/06/2021

This work is licensed under a Creative Commons Attribution 4.0 International License.

\section{Abstract}

Introduction: Dental professionals are considered to be at high-risk for contacting blood-borne pathogen transmissions. Thus, making it necessary for dentists to be aware on prevention, transmission and management of viral hepatitis. Objective: One day training programs for upskilling dental fraternity were conducted on 11th November 2019 and 11thFebruary 2020. Program also evaluated the Knowledge, Attitude, and Practices (KAP) of dentists regarding infection control practices and oral manifestations of viral hepatitis. Methods: One-day training program viz. "Viral hepatitis in Dentistry" under project Programmed Approach to Knowledge And Sensitization on Hepatitis (PRAKASH) was organized and a cross-sectional study using 20-item-self-reported questionnaire was conducted among participating professionals from six states of India. Identifying information was removed during statistical analysis. Results: Total of 625 dental professionals were trained; of which 470 participated in the KAP study i.e. response rate was calculated to be $75 \%$ ( 470 out of 625 ). Females represented about $73.2 \%$ of the sample $(n=470)$. Sample comprised of experts from all the branches of dentistry. Almost $97 \%$ of responders were from private dental institutes or clinics. Mean knowledge score was found to be $4.71 \pm 2.04$, however when compared with age, knowledge in older professionals $>25$ years was higher at $5.00+2.10$ than participants' aged $<25,4.57 \pm 2.00$ ( $p$ value $=0.03$ ). Participating professionals seems to be following precautionary practices regarding viral hepatitis in dental clinics in a comparable manner irrespective of their age i.e. mean practice score of $6.81 \pm 1.82$ in professionals'< 25 years of age and mean practice score $6.81 \pm 1.67$ in trainees $>25$ years. Conclusion: Study raised concerns regarding poor knowledge about infection prevention control and management of viral hepatitis in dental settings. Limited interventions in terms of capacity building programs for dentists on viral hepatitis, highlight the necessity of continued education through such training programs.

\section{Keywords}

Capacity Building; Hepatitis, Human; Health Personnel; Infection Control; Needlestick Injuries, Viral Hepatitis Vaccines.

\section{Introduction}

Among all health care workers dental care experts have an increased risk of contagions through innumerable microorganisms like Hepatitis B virus (HBV) This risk could be heightened by chance injuries during patient handling (1-5), consequently a culture of infection prevention measures and safe practices must be promoted among dental professionals. There has been a thrust for emphasizing safe occupational practices among dental students (6). Numerous studies $(6,7,8,9)$ across the globe have gauged the cognizance of dentists' knowledge, attitudes and behaviours regarding infection control guidelines and precautions and found unsatisfactory 
response. A study by Alavian et al. (10), showcased $81.7 \%$ and $98.6 \%$ of the participants knew about the possibility of HBV transmission through saliva and from dentist to patient respectively, while in study by Al-Shamiri HM et al. (9) the figures were much lower $(42.5 \%$ and $67.6 \%$ respectively. Parallel studies in India(11) reflects either lack of awareness on viral hepatitis among dental professionals or lack of knowledge on management and complications of handling these patients(12). This may reflect the significance of continuous medical education programs in improving the health behaviours among dental health care workers.

Dental experts are exposed to contaminated fluids, aerosols as well as sharp instruments $(13,14)$ these factors contribute to the overall risk of viral hepatitis among them(8) Risk of transmission of viral hepatitis, specially Hepatitis B from positive patients have made the fraternity apprehensive regarding treating patients(15). In India, statistics on Hepatitis' training, knowledge and attitudes in dental professional are limited.

\section{Aim \& Objective}

To assess the knowledge, attitudes and practices regarding Hepatitis infection among dental professionals, students, interns and faculty members.

\section{Material \& Methods}

Training Setting: One-day capacity building program by the name of "Viral hepatitis in Dentistry" was devised under project PRAKASH with the intent of upskilling dental professionals on the concern of viral hepatitis.

So far one in house and an extramural training has been conducted for 625 dental specialists one on 21st November 2019 and on 11thFebruary 2020. The training was aimed to educate the dental professionals on the possible risk of contracting viral Hepatitis infection and also it was intended to raise awareness on the possible safety measures to minimize the risk of spread in the fraternity. The participants were trained on topics including Epidemiology of viral hepatitis in context to dentistry, Oral manifestation of Liver disease, Management of Viral Hepatitis, Infection prevention in dental practice and other parallel topics of concern. Each scientific session was accompanied by queries discussion among participants and subject specialists.

Training Design: Experts comprising of hepatologists and dentists put together the scientific agenda (attached), post which communication on the proposed training was circulated among the targeted beneficiaries i.e. dental colleges and practitioners. Potential trainees had the choice of registration through online or offline method, depending on their convenience.

Post finalization of the training agenda, a team of in-house experts along with the program team deliberated on the suitable resource persons to train the participants. Based on their field of specialization faculty members from Institute of Liver and Biliary Sciences (ILBS), All India
Institute of Medical Science (AlIMS), Sharda University and experts from international NGOs like WHO were agreed upon. After conversing with the trainer's exact theme of each session and its intended objective was formulated. A handbook was prepared by project team, which was further validated and revised, based on the suggestions from the resource persons and concerned experts. The validated version of the handbook was handed over to the participants, which was compiled to serve as a reference material for them, once the training was concluded.

Based on the session objectives and important key points, a Knowledge Attitude Practice (KAP) questionnaire was developed and was shared with session experts for content validation. The KAP questionnaire was revised based on the comments received by the experts. Endorsement of the Program "Viral Hepatitis in Dentistry" was initiated, each training was awarded with 6 Continued Dental Education points. The CDE points are of notice to dental community as Dental Council of India (DCI) - the apex body that regulates dental education. The $\mathrm{DCl}$ has recommended $150 \mathrm{CDE}$ points over a period of 5 years with a minimum of 20 points a year and a maximum of 50 points annually for dental professionals to upgrade themselves on the advancements.

A detailed program brochure of the program was developed and multiple modes of communication like emails, text messages, telephones, messaging applications like WhatsApp were employed to reach out to potential trainees. Multiple dental colleges were also approached to develop a network of dental specialist who can be trained under this program. Mode of registration for the training could be decided by the trainee, as both offline and online registration was possible

During the registration the trainees were asked to mention their name, associated healthcare facility/ institute/ clinical practice as a private practitioner along with the designation at work place, mobile number, Email ID. To assure the participants of their registration a confirmatory email as well a text message in form of Short Message Service was sent, mentioning the details of the training. For the training conducted at ILBS, the participants were provided with the travel reimbursement, amount varying on the basis of their geographical placement. This provision was added to enable more beneficiaries to be benefitted from the program.

Study Type and study population: During this one-day training program a cross-sectional survey of dental students, faculty and clinicians was carried out. A crosssectional descriptive study was performed among dental professionals in India, attending this training.

Study Area: The geographical distribution of trainees was from 6 states and Union territories including Haryana, Punjab, Madhya Pradesh, Chhattisgarh and Uttar Pradesh. The first part covered the demographic characteristics of 
the dental professionals. The next part consisted of 20 closed-ended questions.

Study Duration: 21st November 2019 to 11thFebruary 2020.

Sample size: All the dental professionals and dental students participating in these training programs who voluntarily agreed to be the part of this study here the number of participants was 625 out of which 470 participants took part the study.

Inclusion Criteria: All dental care professionals participating in the viral hepatitis in dentistry training program organized by Institute of liver and biliary sciences between 21st November 2019 to 11thFebruary 2020.

Exclusion Criteria: Incomplete assessment forms

Strategy for collection: This self-administered questionnaire consisted of 20 closed-ended questions divided into four parts. The first part screened the demographic profile of participants including, name, age, gender, institute, academic credentials, experience and contact details. Subsequent section assessed the knowledge of those attendees regarding viral hepatitis infection and its route of transmission. The third part investigated the behaviours and attitude towards hepatitis infection and infected patients. The last part examined the practices of dental workforce regarding protection measures against viral hepatitis. The training program was open to all the dental health care workers, in practise or students across the country. The KAP survey was shared with all the trainees, the study design was previously discussed with the experts at ILBS.

Each question of knowledge part was assigned 1 mark, while attitude questions were based on 5 point- Likert scale for participants to choose from how much they agree or disagree with a particular statement. The practice questions aimed to assess the participant's behaviour towards patient and self-education and following of the best and safe practices in dental clinics. The project team rendered IT support to the trainees, to enable them to record their responses for the questionnaire.

The training compromised of 9 scientific sessions related to viral hepatitis in dentistry, each session was of 45 minutes. The training program was aimed at creating a model of hepatitis awareness among dental professionals and also educating them on safe practices. The sessions were in line with the current guidelines of safe practices and hepatitis management. The trainees were awarded with a certificate of participation mentioning the accreditation of program through $6 \mathrm{CDE}$ points. Before concluding the training, participants were asked to participate in a post test on voluntarily basis to understand the immediate effect of the program on prevailing knowledge of dental professionals. The trainees were also requested to provide feedback for the course, with the aim to improvise upon the existing model for the betterment of program in future.
Ethical approval: The present activity was undertaken as a part of outreach activity, however ethical clearance was obtained with No. F.37/(1)/9/ILBS/DOA/2020/20217/78 dated 01-03-2021 from the institutional ethics committee. Data Analysis software: SPSS (Statistical Package for Social Studies) version 21 was used for data entry and analysis. The continuous data was summarized as mean and standard deviation whereas categorical data was summarized as frequencies with percentage. For the purpose of analysis, the age was categorised into two categories as less than 25 years and 25 years and above. Independent $t$ - test and one-way ANOVA was used to assess the mean difference in pre and post knowledge assessment amongst the participants. statistical significance, with a p-value $<0.05$ was considered statistically significant.

\section{Results}

The response rate was $75 \%$ (470 out of 625 ). Female students represented about $73.2 \%$ of the sample $(n=470)$. The sample comprised of experts from all the recognized branches of dentistry. Almost $97 \%$ of the sample were from private dental institutes or clinics.

Mean age of the participants was calculated as $25 \pm 5.89$ years. Male to female ratio among the trainees was analysed as $1: 3$, of which 126 were males $(26.8 \%)$ and 344 were females (73.2 \%). The capacity building program was attended by trainees from 6 States with major participation from Uttar Pradesh (75.5\%) and Haryana (17.4\%). Most of the attendees were working in Private sector $(97.0 \%)$. Around $65 \%(n=461)$ of participants had completed their BDS or higher degree while the remaining were still pursuing their BDS at the time of training. Though participants were from almost every department of dentistry but majorly from General Dentistry (37.1\%), Periodontics (13.7\%) and Oral Medicine and Radiology (5.2\%). (Table -1 )

Mean knowledge score among trainees was found to be $4.71 \pm 2.04$, however when compared with age, knowledge in older professionals $>25$ years was higher at $5.00+2.10$ than participants' aged $<25,4.57 \pm 2.00$ ( $p$ value $=0.03)$. The mean knowledge score depicts a positive trend with the level of qualification with undergraduates' knowledge score at $4.68 \pm 2.10$ while MDS trainees' mean knowledge score was $4.82 \pm 2.04$. All the participating professionals seems to be following precautionary practices regarding viral hepatitis in dental clinics in a comparable manner irrespective of their age i.e. mean practice score of $6.81 \pm 1.82$ in professionals'< 25 years of age and mean practice score $6.81 \pm 1.67$ in trainees $>25$ years. (Table 2.1) and (Table 2.2)

*Correlation was computed using Pearson analysis and correlation of knowledge score was significant with attitude score at $<0.05$ and correlation of attitude was significant with practice Score at $<0.05$. (Table 3) 


\section{Discussion}

HBV infection is one of the most significant occupational infection faced by dental professionals, as they are frequently exposed to blood, saliva, and even suffer needle stick injuries (16). Accordingly, in order to reduce or prevent the transmission of such microorganisms to dental health workers, strict adherence to infection control guidelines should be applied. This training on viral hepatitis in dentistry and subsequent KAP assessment were conducted to address the lacunae of capacity building programs on viral hepatitis among dental professionals and to additionally assess the level of knowledge, attitude, and practice in dental fraternity regarding viral hepatitis infection in India.

Dental professionals in the present study showed correlation of knowledge score was significant with attitude score at $<0.05$ and correlation of attitude was significant with practice Score at $<0.05$, these results were also reported in other studies Overall, dental $(17,18)$.

The outcomes of our study inferred that there are lacunae in knowledge regarding viral hepatitis infection across all genders, age group and qualification among dental professionals in India, with low knowledge score of $4.71 \pm$ 2.04 during KAP assessment. This is in agreement with some other studies that showed limitation in knowledge among health care workers regarding hepatitis infection and its occupational risk $(6,19)$

Practice score among participants was quite satisfactory i.e. $6.81 \pm 1.77$, despite unsatisfactory knowledge levels, this could be attribute to the fact that people tend to respond in a more socially acceptable manner $(20,21)$. Lack of knowledge about viral hepatitis have appeared to be pervasive among the majority of participants (dentists, etc.) in our study which is in line with other studies conducted globally $(17,22,23)$. This could be attributed to lack of structured training programs concerning viral hepatitis for dental professionals in India (24).

Despite the limitations, there have been many unique aspects and strengths of the study. Firstly, very few trainings and studies have been carried out in India to train the dental professionals on risk, transmission and management of viral hepatitis and to obtain data on knowledge, attitudes, and practice of dentists toward infectious, occupational risk of viral hepatitis.

\section{Conclusion}

The study highlighted the need of carrying out the knowledge, attitude and practices assessment regarding hepatitis risk prevention behaviour among dental health professionals. The outcome of the Study upstretched alarms concerning poor knowledge about infection prevention control and management of viral hepatitis in dental settings. Limited interventions in terms of capacity building programs for dentists on viral hepatitis, highlight the necessity of continued education through such training programs.

\section{Recommendation}

The findings from this study emphasize the necessity of continued education about viral hepatitis in order to improve knowledge, attitudes, and practices of dental professionals regarding the same in clinical settings. Capacity building programs in the form of conferences, round table discussion with virologists and hepatologists are recommended for dental fraternity. Further studies are also required to identify other factors underlining the less-than-optimal awareness about viral hepatitis in dental care settings.

\section{Limitation of the study}

Attrition from registration to participation in KAP and purposive nature of participants selection are the two major shortcomings of the undertaken study. Though 625 participants were registered to be trained under the oneday program "Viral Hepatitis in Dentistry", only 470 participants undertook the KAP assessment, probably due to the voluntary nature of the evaluation. Additionally, the participants of the study were selected through purposive sampling to reach out to dental professionals. The study results are of limited representativeness when compared to other cohorts of healthcare workers.

Also, the tool employed to assess KAP in the was not a validated scale and as mentioned all the trainees didn't participate in the assessment owing to the voluntarily nature of the study. Moreover, all the information that we got are reported by the trainees of our program, and not necessarily reflect the knowledge and attitude level of the entire fraternity.

\section{Relevance of the study}

This paper provides a roadmap to conduct more such trainings in the future throughout the country for capacity building. The training program addresses a common health problem and targets the high-risk group of dental professionals, which can have a significant influence on a serious health concern.

\section{Authors Contribution}

$A B$ has contributed in the concept and design of the study. $S S, P K, A R$ and $A B$ have given the definition of intellectual content, carried out literature search and carried out data acquisition. PK has done the data analysis, while AR and PK have carried out statistical analysis. All the authors contributed in manuscript preparation, editing and review.

\section{Acknowledgement}

The authors sincerely acknowledge Cipla Foundation, for their financial grant provided to Project PRAKASH, However, there is no conflict of interest or financial ties to disclose. Authors also express their gratitude to Dr. S.K.Sarin, Director Institute of Liver and Biliary Sciences for providing his mentorship. Authors also extend their 
thanks to all the faculties and speakers, for their continuous support to the project.

\section{References}

1. MacLachlan, J. H., \& Cowie, B. C.. Hepatitis B virus epidemiology. Cold Spring Harbor perspectives in medicine, 2015;5(5), a021410. https://doi.org/10.1101/cshperspect.a021410

2. Smolle, E., Zöhrer, E., Bettermann, K., \& Haybaeck, J. Viral hepatitis induces hepatocellular cancer: what can we learn from epidemiology comparing iran and worldwide findings?. Hepatitis monthly, 2012;12(10 HCC), e7879. https://doi.org/10.5812/hepatmon.7879

3. Schillie S, Vellozzi C, Reingold A, Harris A, Haber P, Ward JW, et al. Prevention of Hepatitis B Virus Infection in the United States: Recommendations of the Advisory Committee on Immunization Practices. MMWR Recomm Rep 2018;67(1):1-31.

4. Dahiya P., Kamal, R., Sharma, V., \& Kaur, S. "Hepatitis" - Prevention and management in dental practice. Journal of education and health promotion, 2015;4, 33. https://doi.org/10.4103/22779531.157188

5. Smith AJ, Cameron SO, Bagg J, Kennedy D. Management of needlestick injuries in general dental practice. $\mathrm{Br}$ Dent $\mathrm{J}$ 2001;190(12):645-50.

6. Al-aslami RA, Elshamy FMM, Maamar EM, Shannaq AY, Dallak AE, Alroduni AA. Knowledge and Awareness towards Occupational Hazards and Preventive Measures among Students and Dentists in Jazan Dental College, Saudi Arabia. Open Access Maced J Med Sci 2018;6(9):1722-6.

7. Pandharbale AA, Gadgil RM, Bhoosreddy AR, Ahire BS, Kunte VR, Shinde MR. An epidemiological study to assess the awareness of hepatitis B infection in the dental students, college staff, practitioners, and auxiliary staff in city of Maharashtra. J Indian Assoc Public Health Dent 2015;13:179-82

8. Khosravanifard B, Rakhshan V, Najafi-Salehi L, Sherafat S. Tehran dentists' knowledge and attitudes towards hepatitis $B$ and their willingness to treat simulated hepatitis B positive patients. East Mediterr Health J Rev Sante Mediterr Orient Al-Majallah AlSihhiyah Li-Sharq Al-Mutawassit 2014;20(8):498-507.

9. Al-Shamiri H-M, AlShalawi F-E, AlJumah T-M, AlHarthi M-M, AlAli EM, AlHarthi H-M. Knowledge, Attitude and Practice of Hepatitis B Virus Infection among Dental Students and Interns in Saudi Arabia. J Clin Exp Dent 2018;10(1):e54-60.

10. Alavian SM, Mahboobi N, Mahboobi N, Savadrudbari MM, Azar PS, Daneshvar S. Iranian dental students' knowledge of hepatitis B virus infection and its control practices. J Dent Educ 2011;75(12):1627-34.

11. Shitoot A, Motwani M, Chamele D, Shitoot A, Chamele J, Ghosh A. Hepatitis $B$ awareness and attitudes among dental professionals in Central India. J. Indian Acad. Oral Med. Radiol.2016;28(3):270-3.

12. Kasetty S, Mohania A, Dwivedi D, Tijare M, Kallianpur S, Gupta S. A Cross-Sectional Study on the Knowledge of Hepatitis B Infection among Dental Professionals. J Virol Microbiol 2013;1-5.
13. Resende, V. L., Abreu, M. H., Paiva, S. M., Teixeira, R., \& Pordeus, I. A. Concerns regarding hepatitis $B$ vaccination and post-vaccination test among Brazilian dentists. Virology journal, 2010;7, 154. https://doi.org/10.1186/1743-422X-7-154

14. Song, K. B., Choi, K. S., Lang, W. P., \& Jacobson, J. J. Hepatitis B prevalence and infection control among dental health care workers in a community in South Korea. Journal of public health dentistry, 1999;59(1), 39-43. $\quad$ https://doi.org/10.1111/i.17527325.1999.tb03233.x

15. Khosravanifard B, Rakhshan V, Sherafat S, Najafi-Salehi L. Risk factors influencing dentists' hepatitis B-related knowledge and attitudes and their willingness to treat hepatitis B positive patients. Eastern Mediterranean Health Journal = La Revue de Sante de la Mediterranee Orientale = Al-majallah Al-sihhiyah Li-sharq Almutawassit. 2015 Feb;21(1):54-61. DOI: 10.26719/2015.21.1.54. PMID: 25907193.

16. Goel V, Kumar D, Lingaiah R, Singh S. Occurrence of Needlestick and Injuries among Health-care Workers of a Tertiary Care Teaching Hospital in North India. J Lab Physicians 2017;9(1):20-5.

17. Rostamzadeh, M., Afkhamzadeh, A., Afrooz, S., Mohamadi, K., \& Rasouli, M. A. Dentists' knowledge, attitudes and practices regarding Hepatitis B and C and HIV/AIDS in Sanandaj, Iran. BMC oral health, 2018;18(1), 220. https://doi.org/10.1186/s12903-0180685-1

18. Knowledge, Attitude, and Behavior of Hepatitis B Virus Infection Among Chinese Dental Interns. Available from: https://www.ncbi.nlm.nih.gov/pmc/articles/PMC4451273/

19. Hang Pham, T. T., Le, T. X., Nguyen, D. T., Luu, C. M., Truong, B. D., Tran, P. D., Toy, M., Bozkurt, S., \& So, S. Knowledge, attitudes and medical practice regarding hepatitis $B$ prevention and management among healthcare workers in Northern Vietnam. PloS one, 2019;14(10), e0223733. https://doi.org/10.1371/journal.pone.0223733

20. Karp JA, Brockington D. Social Desirability and Response Validity: A Comparative Analysis of Overreporting Voter Turnout in Five Countries. J Polit 2005;67(3):825-40.

21. Grimm P. Social Desirability Bias [Internet]. In: Wiley International Encyclopedia of Marketing. American Cancer Society; 2010. Available

from: https://onlinelibrary.wiley.com/doi/abs/10.1002/9781444316568 .wiem02057

22. Al-Hazmi $\mathrm{AH}$. Knowledge, attitudes and practice of dentists concerning the occupational risks of hepatitis B virus in Al Jouf Province, Saudi Arabia. Niger J Clin Pract 2015;18(2):276-81.

23. Homoud A-HA. Knowledge, attitudes and practice of primary healthcare physicians concerning the occupational risks of hepatitis $B$ virus in Al Jouf Province, Saudi Arabia. J Infect Public Health 2014;7(4):257-70.

24. Malhotra $\mathrm{V}$, Kaura S, Sharma H. Knowledge, attitude and practices about hepatitis B and Infection Control Measures among dental students in Patiala. Journal of Dental and Allied Sciences. 2017;6(2):65-69

\section{Tables}

TABLE 1 BASELINE CHARACTERISTICS OF DENTAL PROFESSIONALS ( $\mathrm{N}=470$ )

\begin{tabular}{|ll|}
\hline General Characteristics & $\mathbf{n}(\%)$ \\
\hline Gender & $25.0 \pm 5.89$ \\
\hline Male & \\
\hline Female & $126(26.8)$ \\
\hline State & $344(73.2)$ \\
\hline Delhi & \\
\hline Haryana & $16(3.4)$ \\
\hline Punjab & $82(17.4)$ \\
\hline Madhya Pradesh & $9(1.9)$ \\
\hline Chhattisgarh & $7(1.5)$ \\
\hline
\end{tabular}




\begin{tabular}{|c|c|}
\hline Uttar Pradesh & $355(75.5)$ \\
\hline \multicolumn{2}{|l|}{ Type of Facility } \\
\hline Government & $14(3.0)$ \\
\hline Private & $456(97.0)$ \\
\hline \multicolumn{2}{|l|}{ Qualification ( $N=461$ ) } \\
\hline BDS Student & $161(34.9)$ \\
\hline BDS and above & $194(42.1)$ \\
\hline MDS and above & $106(23.0)$ \\
\hline \multicolumn{2}{|l|}{ Department $(\mathrm{N}=461)$} \\
\hline General Dentistry & $171(37.1)$ \\
\hline Public Health Dentistry & $19(4.1)$ \\
\hline Conservative and Endodontics & $12(2.6)$ \\
\hline Orthodontics & $18(3.9)$ \\
\hline Periodontics & $63(13.7)$ \\
\hline Prosthodontics & $20(4.3)$ \\
\hline Oral and Maxillofacial Surgery & $22(4.8)$ \\
\hline Pediatric Dentistry & $11(2.4)$ \\
\hline Oral Medicine and Radiology & $24(5.2)$ \\
\hline Oral Pathology and Microbiology & $16(3.5)$ \\
\hline Not Applicable (NA) & $85(18.4)$ \\
\hline \multicolumn{2}{|c|}{ SD: Standard deviation; BDS: Bachelor of Dental Surgery; MDS: Masters of Dental Surgery } \\
\hline Mean Knowledge Score \pm SD & $4.71 \pm 2.04$ \\
\hline Mean Attitude Score \pm SD & $19.22 \pm 3.67$ \\
\hline Mean Practice Score \pm SD & $6.81 \pm 1.77$ \\
\hline SD: Standard deviation & \\
\hline
\end{tabular}

TABLE 2.2 ASSOCIATION OF DEMOGRAPHIC CHARACTERISTICS WITH KNOWLEDGE, ATTITUDE AND PRACTICE SCORE

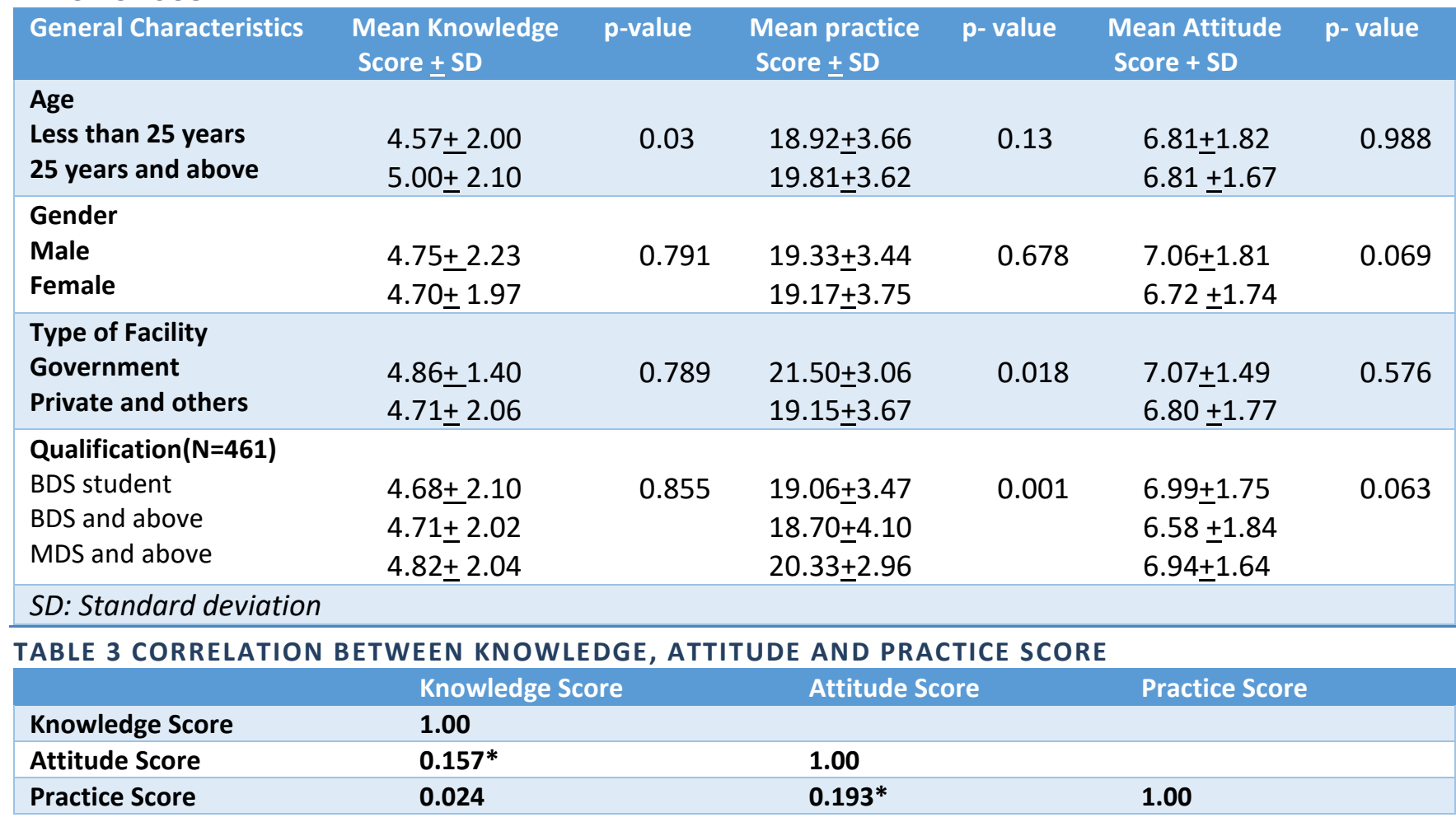

